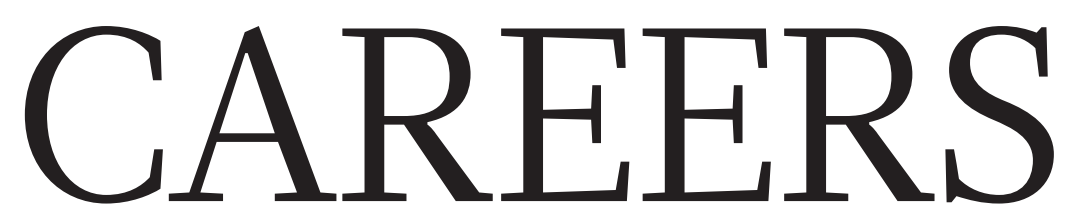

WIDER REACH Chef-turned-researcher targets diverse youth for science $\mathbf{p . 4 0 3}$
BLOG Personal stories and careers counsel http://blogs.nature.com/naturejobs
NATUREJOBS For the latest career

listings and advice www.naturejobs.com

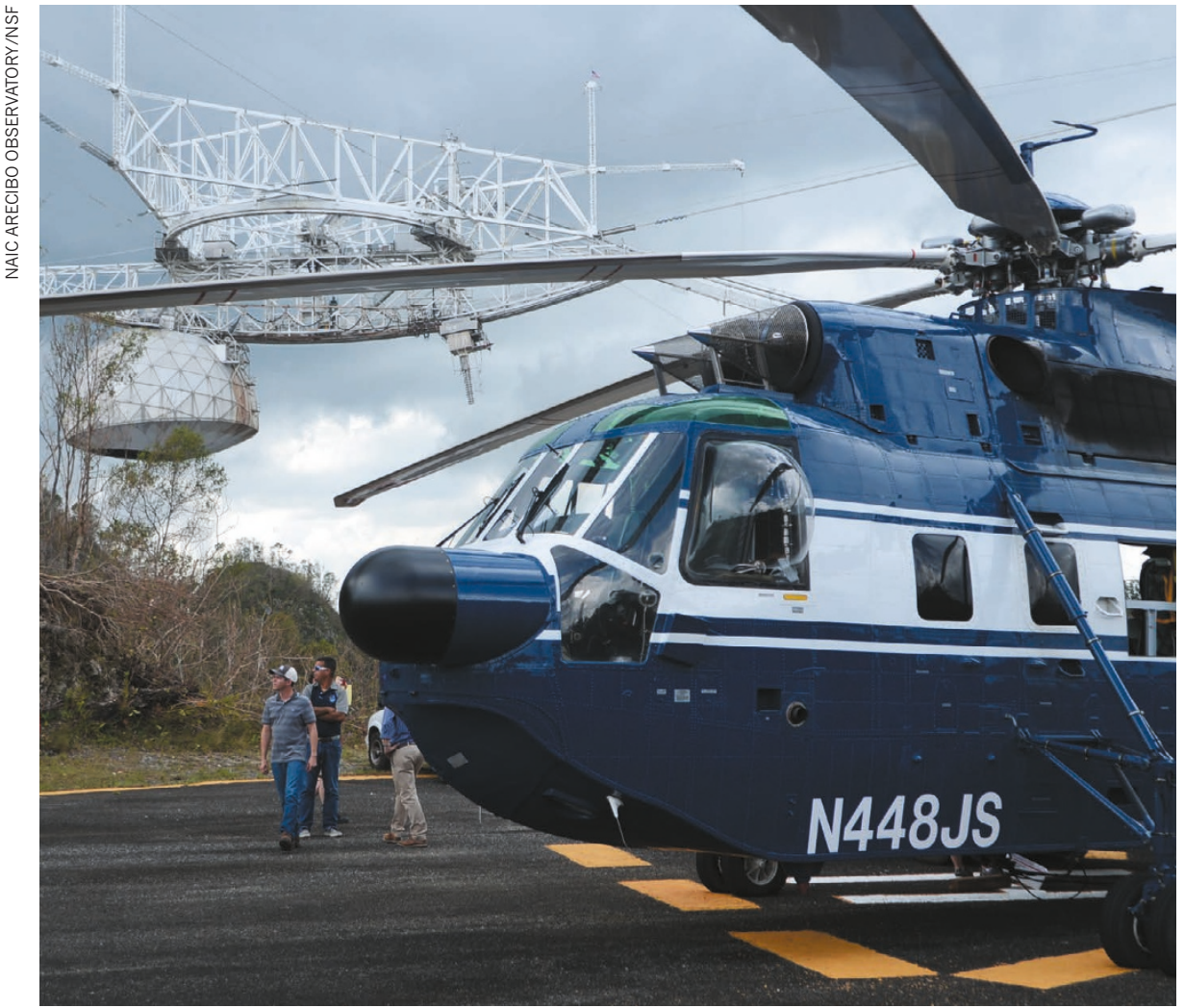

The helipad of the Arecibo Observatory has been used to deliver supplies following Hurricane Maria.

\title{
DISASTER RECOVERY
}

\section{Survival stories: science endures}

\section{Scientists hit hard by powerful hurricanes in 2017 share tips for weathering future disasters.}

$\mathrm{B}$ etween June and September 2017, hurricanes Harvey, Irma and Maria destroyed parts of Texas and Florida and wreaked havoc across entire islands in the Caribbean, including Puerto Rico and the US Virgin Islands. Collectively, the storms killed at least 237 and inflicted billions of dollars' worth of damage. As communities hurried to rescue residents and safeguard homes and property, scientists scrambled to secure experiments, samples, data, technology, equipment and, most importantly, the people who make up research teams.

These storms are just some of the recent disasters around the world, and have imparted lessons that scientists globally might heed. We asked four research leaders whose labs or facilities were directly hit by these hurricanes about the precautions that scientists should take when their labs are in the path of extreme weather or natural disasters.

\section{FRANCISCO CORDOVA Communicate and coordinate}

Director of the Arecibo Observatory in Puerto Rico, the world's largest operational single-dish radio telescope (Hurricane Maria, Category 4).

We have a hurricane-preparedness policy that we follow as soon as tropical-stormforce winds are predicted. In about 12 hours, we lock down the telescope, dismantle the last 3 metres of antenna, install storm shutters, maintain generators, secure fuel, and turn off power to non-essential locations. Before Maria hit, we suspended operations to give staff members time to secure their homes.

The towers and platform are rated for wind speeds of up to 185 kilometres per hour. The strongest winds we received on the site were 174 kilometres per hour. Still, we had damage. Although we had dismantled the last stretch of the antenna, we couldn't completely detach it, so it cracked. Chunks of it then fell, destroying about 20 panels, or $0.05 \%$ of the total area of the dish.

We learnt that communication is key. We knew that the roads leading to the observatory, which are lined with trees and vegetation, would probably be impassable for several days. Before the hurricane, we set up short-wave radio communication so that staff members who live near Arecibo could communicate with each other if we lost Internet access and telephone lines. Still, it was 36 hours before we heard back from staff. One of the lessons we learnt is that we need satellite phones. We've got five of those now, which we used until we were able to establish a wireless Internet connection on the site.

We've come to appreciate how crucial the observatory infrastructure is to the community. We have our own water well, so we've given staff whatever water they want to take home and are currently providing about 64,000 litres of water each day to the community. We've also been working closely with the US Federal Emergency Management Agency, which has used our helipad to deliver supplies for distribution.

The hurricane hit as we await a funding 
$\checkmark$ decision that will determine the observatory's fate. Yet it highlighted this facility's value - nobody expected us to be able to collect data again one week later, but we did, thanks to our staff members' dedication in trying circumstances. However, we are not running a full observation schedule because we still don't have commercial power, and fuel supplies on the island are unstable.

\section{DAVID VAUGHAN}

\section{Spread the risk} to avoid disaster

\section{Executive director of the Mote Elizabeth Moore International Center for Coral Reef Research \& Restoration in Summerland Key, Florida (Irma, Category 5).}

Our new concrete building, rated to withstand 350-kilometre-per-hour winds and a 1.2-metre storm surge, did its job. The building was completed in May, and Irma struck in September - I never thought we'd have a test of the facilities so quickly. The area was without power for almost a week after the hurricane, but we were without it for only 1.5 days because we had a back-up generator and low power needs.

We had some damage to our raceways long, rectangular flow-through tanks where we store our corals - as well as to experimental systems, vessels and equipment outside the main building.

Most groups doing coral restoration do not have a land-based hatchery or nursery. We were one of the first to work with 28 endangered coral species to create a gene bank. But we were able to do so only because we have a land-based facility that is able to handle the mass of corals we are raising at the same time.

In addition, we diversified by having two field nursery sites - one lost just $10 \%$ of the population; the other may have only $10 \%$ survival. It's good to spread out the risk with multiple nursery locations.

For us, the most important consideration was how to keep the most corals alive throughout the storm. So we moved well over half the corals inside the building to what I call a 'wet-lab bunker'. The remaining corals were split between an 86,000-litre tank and the few that we left in outside raceways. We didn't want to put all our eggs in one basket in case something happened inside.

During the storm, the outdoor raceway tanks tumbled over. Realizing that the corals in the raceways wouldn't survive, we took advantage of a short period before the worst of the storm hit to move all those corals. We literally threw thousands of corals into the large tank, and managed to save all but $13 \%$ that had been outside.
The day after the storm, a colleague and I spent 8 hours swimming in the tank, stabilizing all the corals that we had thrown in. In retrospect, I would still hedge my bets and not put all the coral in one place. If I had had $100 \%$ inside and the generator had failed, I would have lost everything.

Another way to lower risk is to reduce the energy needs of the facility. We put solar panels on the top of the building that can provide 30 kilowatts of energy; the roof collects rain to flush the toilets; and the entire building uses LED lights to reduce electrical consumption. We could have lasted a long time if it had been weeks before power was restored.

\section{SOPHIAPERDIKARIS Work with local communities}

\section{Chair of the anthropology and} archaeology department at City University of New York's Brooklyn College; director of the Barbuda Archaeological Research Center in West Indies (Irma, Category 5).

Irma destroyed more than $95 \%$ of structures and vehicles on the island of Barbuda, which is about 480 kilometres southeast of Puerto Rico. Three weeks later, I was allowed to go on the island. I needed to survey what was left because the entire vegetative cover had been stripped. We hoped to see what had been unearthed by the hurricane, and identify any new archaeological sites that needed protection before rebuilding begins.

It was devastating in terms of material debris. It looked as though a ginormous weed-whacker had piled up 2 metres of uprooted vegetation and stripped trees bare. A lot of animals died. The dune sites were most impacted. In one area, we lost about 7.5 metres of beach that extended into the sea. It's now more like a cliff. For the first time in 5,000 years, no one lived on the island.

We did not lose any artefacts or bone material in any of the three locations where they were stored. We did lose a weather station, water meters and drone equipment.

We need multiple ways to back up data we've collected and keep them safe in a variety of locations. We can't do that with artefacts, because cultural heritage has to stay on the island. One way to protect the data is to publish as often and as swiftly as possible.

We need to collect a whole new set of environmental data - from coastal erosion to vegetation cover. We need a complete environmental assessment to establish new baselines of island conditions to prepare for future events and to safeguard archaeological sites as rebuilding gets under way. There's

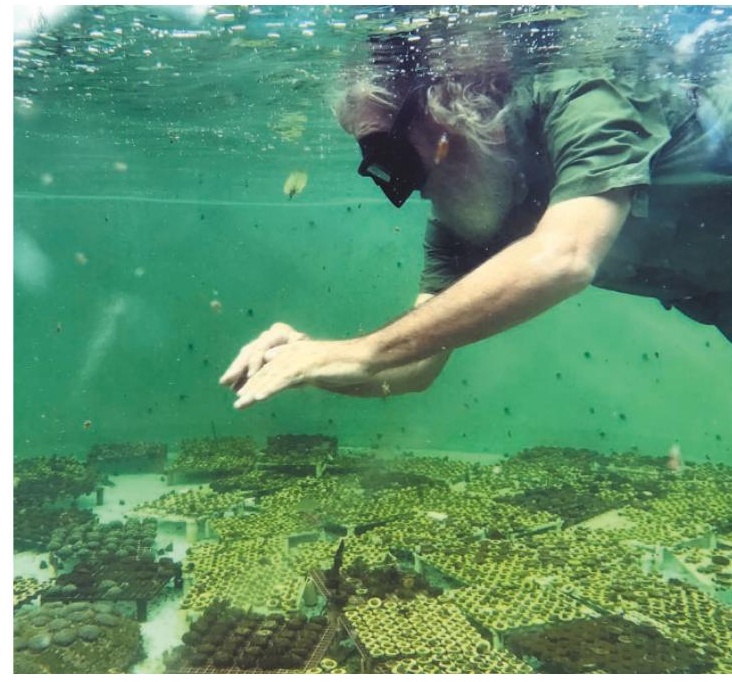

David Vaughan works to stabilize coral samples displaced by Hurricane Irma.

also an opportunity to assess whether historical wells can have a role as the community grapples with modern water shortages.

In addition to conducting archaeological research, we work closely with schools on programmes that connect archaeology with the environment. I have to commend all of the locals who worked with us to secure the facility and preserve our work - it's incredible to me that they took time to help protect our scientific station, even as they faced their own personal struggles. One takeaway lesson is that when scientists do science relevant to local people - when the community works with the scientists - the community owns the science and the discoveries because they are personally invested.

\section{LEEFUIMAN \\ Learn from past disasters}

Director of the fisheries and mariculture laboratory at the University of Texas at Austin's Marine Science Institute (MSI) in Port Aransas (Harvey, Category 4).

The major hit to our research capabilities was the loss of live fish - roughly two-thirds of our stock. We also had to euthanize at least three experiments' worth of larval and juvenile fish to prevent them from starving.

These losses set our research back months, and possibly years in some cases - but the damage could have been much worse had we not taken certain precautions. After Hurricane Katrina in 2005 - one of the five deadliest storms in US history, and the most costly up to that point - when I was director of the entire MSI, we developed our first formal hurricane action plan. That laid out 
how to communicate during and after a hurricane, as well as scenarios for recovery.

Hurricane preparedness, which was dramatically revised by our current MSI director, is now a routine exercise for us. Three days in advance of the storm reaching us, we back up data on our computers. Two days before, we secure hazardous chemicals and equipment. One day before, we move glass and small electronic instruments off counters and into drawers, shut down major pieces of equipment - such as the gas chromatograph and quantitative polymerase chain reaction machines - and move valuable samples and expensive reagents to the refrigerator. Some people take especially valuable samples with them. As for the fish, our first goal is to give them the best chances for survival by making sure there is plenty of diesel fuel for the emergency generator.

We find that graduate students, who 3 are not from the area and haven't been through a hurricane, need a bit of guidance and reassurance. There is the psychological aspect you have to prepare for, realizing that some people will need extra support.

In the aftermath of Harvey, John Sharp, the chancellor of Texas A\&M University, offered offices and labs for our faculty members, staff and graduate students. It was helpful because Texas A\&M has a campus in Corpus Christi, just 50 kilometres from Port Aransas. Many MSI researchers relocated there, but we were fortunate to get back into our lab three weeks after the hurricane. Our ability to get back in swiftly had much to do with having our hurricane action plan in place.

Now that we've assessed the damage, we will be redesigning our seawater intake systems to minimize damage in the future. Before the storm, we had plans for a new structure to house the seawater pumps and blowers. The current shed was lost to Harvey. Had we completed that project before this storm, we probably would not have lost the fish.

The seawater tank is on the roof of our building so that we can use gravity to supply all of our labs. The problem is that the storm blew the roof off the tank, and it filled with debris. It took quite some time to drain, repair, clean and refill the tank before we could re-establish the seawater supply to our labs and begin cleaning those tanks. We are now designing an improved seawater containment system - incorporating either a better roof cover or a giant flexible container that completely encloses the seawater.

\section{INTERVIEWS BY VIRGINIA GEWIN}

These interviews have been edited for clarity and length.

\section{TURNING POINT} Gourmet investigator

Vayu Maini Rekdal moved from Sweden to New York City after high school to pursue his interest in cooking, before turning to chemical biology. He is now studying for a $\mathrm{PhD}$ at Harvard University in Cambridge, Massachusetts. In August, Rekdal, the son of an Indian mother and a Cuban-Norwegian father, received a Howard Hughes Medical Institute Gilliam fellowship for outstanding scientists, an award that aims to advance diversity in academia. He explains why it's important to engage primary-school students' interest in science.

\section{How did cooking cultivate your interest in science?}

I grew up in Stockholm in a cross-cultural family. My mum, who was born in Kenya, emigrated to Sweden in the 1960s. My dad is Cuban-Norwegian. I got in touch with my heritage through cooking, which I viewed as experimentation - I didn't know I was doing science. After high school, I moved to New York City to follow my goal of becoming a chef. But a restaurant is a fast-paced, intense environment that didn't offer time for thinking creatively. So I decided to apply to university to see how else I could explore my interests in food.

\section{Where did those explorations take you?}

I ended up at Carleton College in Northfield, Minnesota. As an undergraduate, I won a scholarship to go to Món Sant Benet, Spain, and work at the Alícia Foundation, a unique place that uses science to deconstruct and understand food. It was a pivotal choice. I went there thinking I would learn how to be a better chef, and came out realizing that cooking and science are one and the same. In June 2013, I went to Mayo Clinic in Rochester, Minnesota, to study gut microbes. When I was in my third year, I joined a chemical-biology lab at Harvard to continue studying gut microbes.

\section{What motivated you to create a Young Chefs programme as an undergraduate?}

Cooking made science relevant to me. I decided that it would be a fantastic way to get others interested in science as well. Initially, I worked with underserved young Somali and Latino immigrant students aged 11-14. Together with some professors and other students at Carleton, I developed a rigorous, hands-on scientific curriculum that addressed physical and life-science concepts. We now have 27 lesson plans that we made free and open access. It's been used by 300 educators around the world. It's something I'll do for the rest of my life.

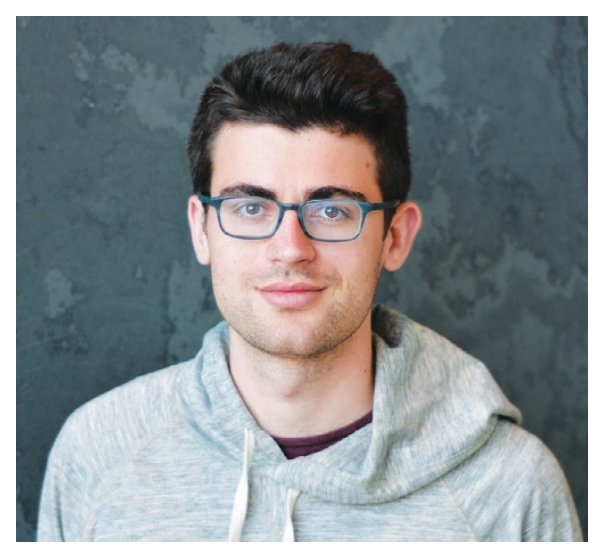

What is your $\mathrm{PhD}$ research focused on?

I'm interested in the connection between gut microbes and human biology - specifically, how microbes in the gut metabolize molecules we ingest. When we consume something be it a drug, food or a toxin — the body can't access those molecules immediately. They are first transformed by gut microbes, which in turn alter the molecular properties of the gut, with profound implications for health and disease.

What are your thoughts on the current status of diversity in academic science?

It's striking how much less diversity you find higher up in academia. As well as a lack of racial diversity, there's also a lack of diversity in socioeconomic or educational backgrounds. We need to get people interested in science at an earlier age to maintain a larger pool of young scientists.

\section{As a Gilliam fellow, how do you hope to} increase diversity and inclusivity in academia? We need to get high-school and primary-school educators into the kitchens. I'm creating a dedicated teaching programme here at Harvard with partners to give underserved communities access to resources. We are launching a pilot this autumn with a group of teachers, tentatively called STEAMED, a play on cooking and STEM - science, technology, engineering and mathematics. This summer, we worked with Native American high-school students. More immediately, given how important mentors were for me, I'm hoping to mentor undergraduates and summer-school students.

\section{Will you aim for a conventional academic career path?}

I want to carve out my own.

\section{INTERVIEW BY VIRGINIA GEWIN,}

This interview has been edited for clarity and length. 